\title{
Case report of subcutaneous entomophthoromycosis with retroperitoneal invasion
}

\author{
Relato de caso de entomoftoromicose subcutânea \\ com invasão retroperitoneal
}

\author{
Leonora Maciel de Souza Vianna ${ }^{1,2}$, Marcus Vinícius Guimarães de Lacerda ${ }^{1}$ \\ and Mário Augusto Pinto de Moraes ${ }^{1}$
}

\begin{abstract}
The authors describe a case of entomophthoromycosis in a previously healthy patient, who presented with an abscess in the right buttock. After surgical drainage it evolved into a retroperitoneal tumor. The patient improved clinically after resection of the mass and ketoconazole treatment. The histopathological analysis showed the Splendore-Hoeppli phenomenon, suggesting Basidiobolus ranarum infection, a zygomycosis generally restricted to the subcutaneous tissue, with rare gastrointestinal involvement.
\end{abstract}

Key-words: Basidiobolus ranarum. Zygomycosis. Entomophthorales. Clinical features. Histopathology. Splendore-Hoeppli phenomenon.

\section{RESUM0}

Os autores descrevem um caso de entomoftoromicose em paciente previamente saudável, que apresentou abscesso em nádega direita, evoluindo, após drenagem cirúrgica, para tumoração retroperitoneal. Após ressecção da massa, o paciente obteve melhora clínica, em uso de cetoconazol. A análise histopatológica evidenciou fenômeno de Splendore-Hoeppli, sugerindo infecção por Basidiobolus ranarum, uma zigomicose geralmente restrita ao tecido subcutâneo, com raro comprometimento gastrintestinal.

Palavras-chaves: Basidiobolus ranarum. Zigomicose. Entomophthorales. Características clínicas. Histopatologia. Fenômeno de Hoeppli-Splendore.

We refer to human zygomycosis as polymorphic diseases caused by fungi of the Zygomycetes class. This class is subdivided into two orders: Mucorales and Entomophthorales ${ }^{10}$. Unlike the Mucorales order, which has the ability to cause systemic disease, this last order is mainly represented by Conidiobolus coronatus, the etiologic agent of subcutaneous infections confined to the nasal mucosa and adjacent tissues, and Basidiobolus ranarum (also known as Basidiobolus haptosporus), which involves the trunk and limbs, and rarely the gastrointestinal tract ${ }^{415}$.

We report a rare form of entomophthoromycosis suggesting Basidiobolus ranarum infection, which extended to the retroperitoneum, after subcutaneous infection in the right buttock.

\section{CASE REPORT}

A 43-year-old male farmer from the rural area of Unaí, in State of Minas Gerais, developed an abscess in the right buttock, without previous local trauma, and was admitted to the Hospital of Sobradinho, Brasilia, Brazil, in July 1989. The patient's medical history was unremarkable and he was previously healthy. №

1. Centro de Anatomia Patológica do Hospital Universitário de Brasília da Universidade de Brasília, Brasília, DF. 2. Unidade de Anatomia Patológica do Hospital Regional de Sobradinho da Secretaria de Estado de Saúde do Distrito Federal, Brasília, DF.

Address to: Dra. Leonora Maciel de Souza Vianna. Centro de Anatomia Patológica/Hospital Universitário de Brasília. Via L2 Norte, SGAN 604/605, Módulo C, 70840-050 Brasília, DF.

Tel. 5561 448-5501

e-mail: caphub@unb.br

Recebido para publicação em 10/10/2003

Aceito em 3/5/2005 
systemic illness was observed. Roentgenographs of the pelvis showed a soft-tissue abscess without bone or joint lesions. The abscess was surgically drained and the lesion improved without specific medication. The contents of the drainage were not sent for culture. Histopathologic analysis of a subcutaneous tissue sample showed nonspecific chronic inflammation.

In February 1990, seven months after discharge, the patient started to complain of arthralgia in the right knee, abdominal pain, malaise, uncharacteristic fever, vomiting and weight loss. He was admitted to the same hospital, where a diagnostic procedure was performed.

On physical examination, the patient had a poor nutritional state, weighing only $45 \mathrm{~kg}$, with normal vital signs. No lymphadenopathywas found. The lungs and heart and neurologic examination were normal. His abdomen was tender, particularly in the right flank, where a palpable, nodular mass was located. The liver extended $5 \mathrm{~cm}$ below the right costal border.

Hematologic laboratory data obtained on admission were as follows: hematocrit 0.41 and white-cell count $10.8 \times 10^{9} / \mathrm{L}$, with a normal differential count. The blood chemistry values were normal, as well as the coagulation profile and urinalysis. The tuberculin skin test was negative at 48 hours. Ultrasound of the abdomen confirmed the presence of a thick mass in the right flank $\left(405 \mathrm{~cm}^{3}\right)$.

He subsequently underwentan exploratory laparotomy, where a mass was found in the retroperitoneum, upon the right kidney. It was excised and sent for histopathological analysis. The resected material consisted of an irregular mass, which was whitish, smooth, firm and measured approximately $10 \mathrm{~cm}$ in the greatest diameter. Microscopically, hematoxylin and eosin (H\&E) stained sections showed a dense eosinophilic infiltrate. Many noncaseating granulomas were present (Figure 1) and multiple areas demonstrating Splendore-Hoeppli phenomenon were observed, with a thick, eosinophilic, hyalinized sheath surrounding the thin-walled fungal hyphae (Figures 2 and 3). No vascular invasion or fungal thrombosis were seen. A culture of the specimen was not performed. Based on the localization of lesions, the agent aspect in the tissues, and histopathologic picture, Basidiobolus ranarum was suggested.

The patient received ketoconazole ( $400 \mathrm{mg} / \mathrm{d}$ ) for 35 days with a complete clinical improvement.

\section{DISCUSSION}

Mucormycosis (infection with fungi of the order Mucorales) is characterized by a rapidly progressive and usually fatal course, primarily in immunocompromised patients. Common clinical manifestations include rhinocerebral, pulmonary, gastrointestinal and cutaneous involvement as well as dissemination. Due to its vasculotropism, the hyphal infiltrations found near blood vessels and septic thromboembolism are common ${ }^{69}$.

On the other hand, entomophthoromycosis (infection with fungi of the order Entomophthorales) has a more benign course and apparently no underlying disease appears to predispose to

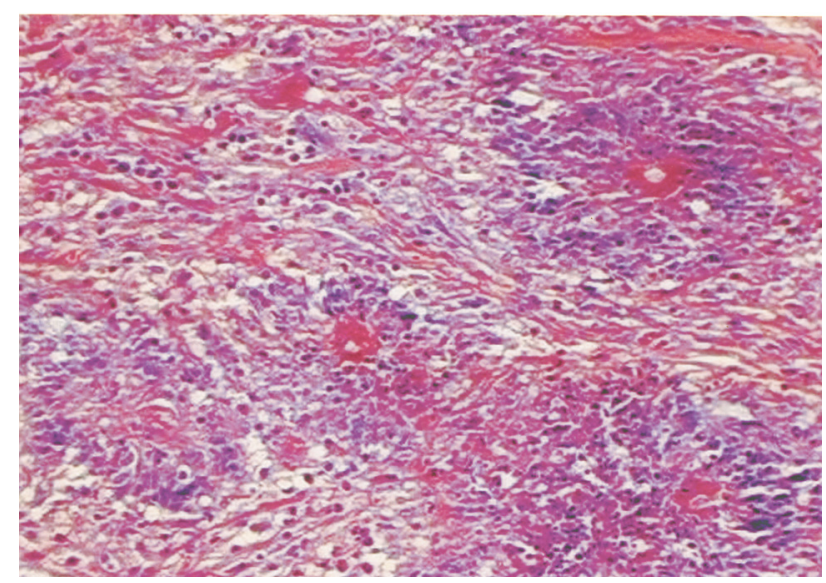

Figure 1- Section from the resected retroperitoneal tumor, showing several large hyphae within microabscesses and a surrounding mononuclear infiltrate (H\&E, 40x).

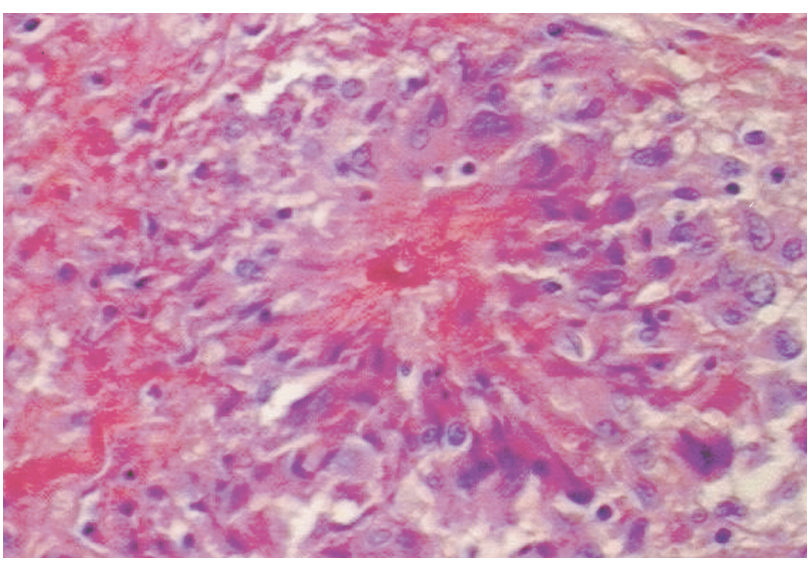

Figure 2- Hyphal form of Basidiobolus is observed in the center of a granuloma. The amorphous material surrounding the emptyappearing hyphal structure is eosinophilic on H\&E staining (Splendore-Hoeppli phenomenon) (200x).

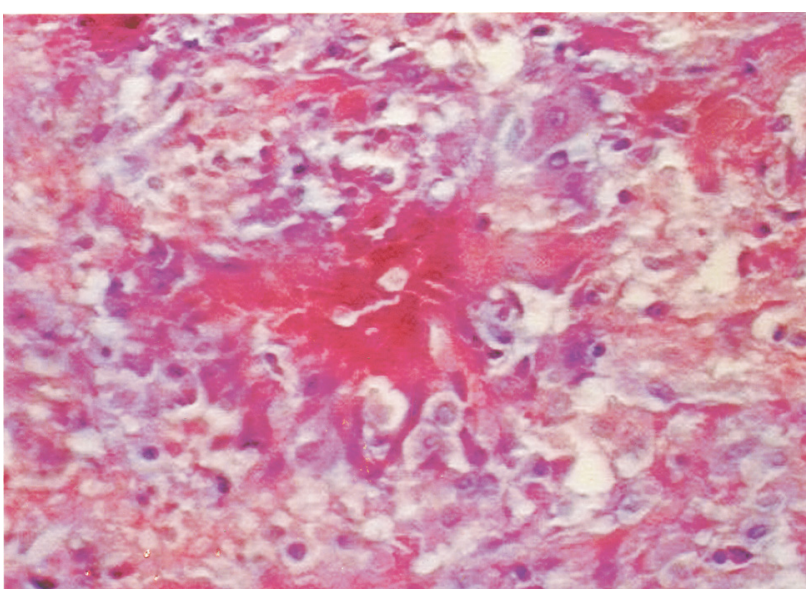

Figure 3 - In this section, the thin walled hyphae, surrounded by Splendore-Hoeppli phenomenon, are more evident (H\&E, 200x).

the infection. In 1988, of 33 Latin American cases reported, 84\% were described in Brazil ${ }^{1}$. The tissue reaction is almost pathognomonic, consisting of a chronic granulomatous reaction with thin-walled, often septate hyphae or hyphal fragments (4-10 $\mu \mathrm{m}$ in diameter) with a thick eosinophilic sheath (Splendore-Hoeppli phenomenon) staining intensely pink in H\&E sections and bright red in PAS-stained sections ${ }^{13}$. 
The infection due to B. ranarum is widely prevalent in tropical and subtropical regions and is often misdiagnosed or not reported. Infection usually begins as small papules following a scratch or puncture by an insect, plant, or other fungus-bearing object. The lesion commonly develops in the perineum, buttocks, trunk and thighs, probably due to the habit of using decaying plant leaves lying on the ground as toilet paper after defecating in the open?

Since the fungus cannot withstand refrigeration, biopsied material should be cultured immediately after collection. This probably contributes to the absence of the definitive diagnosis in most of the cases where there is no previous suspicion of fungal infection ${ }^{710}$.

Visceral disease caused by B. ranarum is rare, but cases of gastrointestinal infection have been reported worldwide ${ }^{3581315}$. It is not clear how the fungus gains access to the gastrointestinal tract of patients. It is attributed to ingestion, with the portal of entry being the stomach, or to direct inoculation via minor rectal trauma.

Possibly due to protease enzymes produced by B. ranarum and other Entomophthorales ${ }^{12}$, the fungus is able to invade soft tissues and eventually evolve beyond a subcutaneous infection. One patient with a voluminous lesion resembling a soft tissue tumor has been reported elsewhere $e^{2}$. Two patients similar to ours have been reported, one with retroperitoneal lesions and one with pelvic cavity lesions. A surgical procedure prior to the clinical detection of the internal masses was observed in both ${ }^{11}{ }^{14}$. We consider that the rare forms of intra-abdominal entomophthoromycosis withoutinvolvement of the gastrointestinal tract are probably related to invasive procedures, which possibly implant the fungus more deeply.

\section{ACKNOWLEDGMENTS}

We thank Col. D. Skillman, Walter Reed Army Institute of Research, for critical review of the manuscript.

\section{REFERENCES}

1. Bittencourt AL. Entomophthoromycosis. Review. Medicina Cutânea IberoLatino-Americana 16: 93-100, 1988.

2. Bittencourt AL, Andrade JA, Carvalho EM. Basidiobolomycosis. Report of a case with unusual aspect. Revista do Instituto de Medicina Tropical de São Paulo 29: 381-384, 1987.

3. Carvalho FA, Macedo JL, Costa JN, Moraes MA. Intestinal entomophthoromycosis: report of a case. Revista da Sociedade Brasileira de Medicina Tropical 30: 65-68, 1996.

4. Chapman RS, Kaplan W, Ajello L, Chandler FW. Zygomycosis. In: Color Atlas \& Textbook of the Histopathology of Mycotic Diseases, Year Book Medical Publishers, Inc, Chicago, p. 122-127, 1980.

5. Chiewchanvit S, Khamwan C, Pruksachatkunakorn C, Thamprasert K, Vanittanakom N, Mahanupab P, Lertprasertsuk N, Fooanant S. Entomophthoromycosis in Maharaj Nakorn Chiang Mai Hospital. Journal of the Medical Association of Thailand 85: 1089-1094, 2002.

6. Eucker J, Sezer 0, Graf B, Possinger K. Mucormycoses. Mycoses 44: 253260, 2001.

7. Gugnani HC. A review of zygomycosis due to Basidiobolus ranarum. European Journal of Epidemiology 15: 923-929, 1999.

8. Khan ZU, Khoursheed M, Makar R, Al-Waheeb S, Al-Bader I, Al-Muzaini A, Chandy $\mathrm{R}$, Mustafa AS. Basidiobolus ranarum as an etiologic agent of gastrointestinal zygomycosis. Journal of Clinical Microbiology 39: 2360-2363, 2001.

9. Kobayashi M, Hiruma M, Matsushita A, Kawai M, Ogawa H, Udagawa S. Cutaneous zygomycosis: a case report and review of Japanese reports. Mycoses 44: 311-315, 2001.

10. Lacaz CS, Porto E, Martins JEC, Heins-Vaccari EM, Melo NT. Zigomicoses. In: Lacaz CS (ed) Tratado de Micologia Médica, $9^{\text {th }}$ Edition, Sarvier, São Paulo, p. 761-783, 2002.

11. Nazir Z, Hasan R, Pervaiz S, Alam M, Moazam F. Invasive retroperitoneal infection due to Basidiobolus ranarum with response to potassium iodide - case report and review of the literature. Annals of Tropical Paediatrics 17: 161-164, 1997.

12. Okafor JI. Purification and characterization of protease enzymes of Basidiobolus and Conidiobolus species. Mycoses 37: 265-269, 1994.

13. Oliveira AM. Zigomicose granulomatosa visceral. Revista de Patologia Tropical 17: 187-300, 1988.

14. Soares HL, Miranda D, Nunes A. Tropical phycomycosis involving the pelvic cavity and thighs in a Brazilian child. The American Journal of Tropical Medicine and Hygiene 23: 701-703, 1974.

15. Zavasky DM, Samowitz W, Loftus T, Segal H, Carroll K. Gastrointestinal zygomycotic infection caused by Basidiobolus ranarum: case report and review. Clinical Infectious Diseases 28: 1244-1248, 1999. 